\title{
Altitude e solos determinam variações abruptas da vegetação em gradiente altitudinal de Mata Atlântica ${ }^{1}$
}

Altitude and soils determines abrupt variation of vegetation in altitudinal gradient in Atlantic Rain Forest

\author{
Eder Caglioni ${ }^{2,6}$, Alexandre Uhlmann ${ }^{3}$, Gustavo Ribas Curcio ${ }^{2,3}$, Michele Ribeiro Ramos ${ }^{4}$, \\ Annete Bonnet ${ }^{3} \&$ Anilton Ricardo Junckes ${ }^{5}$
}

\begin{abstract}
Resumo
A variação da vegetação em gradientes altitudinais geralmente é condicionada pelo gradiente térmico. Neste estudo, hipotetizamos que a estrutura da vegetação varie abruptamente como resultado de ambientes muito distintos cuja formação não está relacionada somente com a altitude e o clima. Definimos três áreas no Parque Botânico Morro do Baú, Ilhota, SC. Em cada, alocamos 50 parcelas de $100 \mathrm{~m}^{2}$ (Área 1 - $340 \mathrm{~m}$; Área 2 - 540 m; Área 3 - 810 m s.n.m.). Medimos os espécimes com PAP $\geq 15 \mathrm{~cm}$. Elaboramos diagrama de Venn e comparamos as Áreas por meio de curvas de rarefação. Aplicamos DCA e ordenação por NMDS para identificar o grau de variação na vegetação. Devido à forte distinção das demais, comparamos a Área 3 com outros levantamentos. A estrutura arbórea varia abruptamente entre as Áreas $1 / 2$ e a 3, sendo esta última uma verdadeira floresta altomontana determinada pelos efeitos conjuntos de altitude, clima, solos e geomorfologia. Regionalmente, entretanto, as similaridades não são maiores com outras florestas altomontanas, mas sim com áreas próximas e de altitude aproximada.
\end{abstract}

Palavras-chave: Floresta Ombrófila Densa Altomontana, Morro Testemunho, Vale do Itajaí.

\begin{abstract}
The variation of vegetation in altitudinal gradients is usually conditioned by the thermal gradient. We hypothesized that the vegetation structure varies abruptly as a result of very distinct environments whose formation is not only related to altitude and climate. We selected three areas in the Morro do Baú, in Ilhota municipality, Southern Brazil. In each, we allocated 50 plots of $100 \mathrm{~m}^{2}$ (Area 1 - $340 \mathrm{~m}$ a.s.1., Area 2 - 540 $\mathrm{m}$ a.s.l. and Area 3 - $810 \mathrm{~m}$ a.s.1.). We measured all individuals with $\mathrm{DBH} \geq 4,77 \mathrm{~cm}$. We elaborated a Venn diagram and compare areas using rarefaction curves. We applied DCA and NMDS ordination to identify the degree of vegetation variation. Because of its strong distinction, we compared Area 3 with part of the data from IFFSC. The vegetation structure varies abruptly between Areas $1 / 2$ and 3 , the latter being a true cloud forest determined by the joint effects of altitude, climate, soils and geomorphology. Regionally, however, the similarities are not greater with other cloud forests, but with areas near and of approximately the same altitude. Key words: cloud forest, Inselberg, Itajaí Valley.
\end{abstract}

\footnotetext{
${ }^{1}$ Parte da tese de Doutorado.

${ }^{2}$ Universidade Federal do Paraná, Prog. Pós-graduação em Engenharia Florestal, Av. Pref. Lothário Meissner 900, 80210-170, Jardim Botânico, Curitiba, PR, Brasil.

${ }^{3}$ Empresa Brasileira de Pesquisa Agropecuária - EMBRAPA Florestas, Estr. da Ribeira, km 111, C.P. 319, 83411-000, Colombo, PR, Brasil.

${ }^{4}$ Universidade Estadual do Tocantins - Unitins, Q. 108 Sul, Alameda 11 s/n, 77020-122, Centro, Palmas, TO, Brasil.

${ }^{5}$ Defesa Civil - Prefeitura Municipal de Ilhota/SC, R. Dr. Leoberto Leal 160, 88320-000, Centro, Ilhota, SC, Brasil.

${ }^{6}$ Autor para correspondência: eder.caglioni@gmail.com;
} 


\section{Introdução}

O estado de Santa Catarina está inserido no domínio Atlântico e tem as encostas e planícies de sua faixa leste cobertas pela Floresta Ombrófila Densa (Klein 1978). Esta é a região fitoecológica com maior diversidade de espécies florestais do estado (Gasper et al. 2012), o que é possivelmente favorecida pela heterogeneidade ambiental (Herrmann \& Rosa 1990; Klein 1979, 1980; Oliveira-Filho \& Fontes 2000) com destaque para os efeitos da variação de temperatura e umidade (Klein 1979, 1980; Oliveira-Filho \& Fontes 2000; Uhlmann et al. 2012).

A organização de espécies florestais em uma mesma encosta revela especificidades interativas com a geologia, geomorfologia, hidrologia e pedologia, incorrendo em variações florísticas e estruturais consideráveis (Klein 1980; KotchetkoffHenriques et al. 2005; Curcio et al. 2006; Eisenlohr et al. 2013; Vieira et al. 2014; Maçaneiro et al. 2016). Nestas encostas, em relevos menos inclinados, geralmente em menores altitudes, predominam solos mais profundos, argilosos e bem drenados devido à declividade, propiciando condições favoráveis para o desenvolvimento da vegetação e afetando suas principais características como a maior riqueza, o maior porte e, consequentemente, a menor densidade de indivíduos arbóreos (Klein 1979, 1980; Rodrigues et al. 2007). Já nas maiores declividades, os solos se adelgaçam influenciando o desenvolvimento da vegetação arbórea, gerando fisionomias constituídas por árvores de menor porte e aumento da densidade (Klein 1979, 1980), além de menor riqueza (Blum et al. 2011; Joly et al. 2012).

Em grandes elevações, a cobertura florestal possui fitofisionomia distinta (Roderjan et al. 2002; Scheer \& Mocochinski 2009; Scheer et al. 2011b). Nestes ambientes, a fisionomia é resultado da presença de troncos e ramos bastante retorcidos e dossel homogêneo, onde virtualmente não há árvores emergentes, existindo apenas um estrato com copas bastante densas (Koehler et al. 2002; Roderjan et al. 2002; Scheer et al. 2011b). Outra peculiaridade é a diminuição no tamanho das folhas determinando o aumento da área superficial específica que, juntamente com a grande quantidade de epífitos que cobrem completamente os troncos das árvores, proporcionam uma "rede" de captura de umidade, proveniente das frequentes nuvens que se formam ao redor do anteparo físico formado pelas elevações. A umidade deposita- se gota-a-gota nestas superfícies, aumentando o aporte hídrico nesses locais (Hamilton et al. 1995; Juvik \& Nullet 1995; Hölscher et al. 2004). Associada a este processo, a redução da radiação solar, da evapotranspiração e da temperatura (o esfriamento adiabático - ver Soares \& Batista 2004), também provocam a diminuição das taxas de decomposição da biomassa, causando acúmulo de matéria orgânica nos solos, consequentemente aumentando a retenção hídrica (Edwards \& Grubb 1977; Bruijnzeel \& Proctor 1995; Hamilton et al. 1995; Scheer et al. 2011a, 2013).

Entretanto, estas características observadas nas florestas altomantanas, que na latitude do presente trabalho deveriam ocorrer acima de 1.000 $m$ de altitude (IBGE 2012), também podem ser encontradas em altitudes mais baixas que o habitual (Flenley 1995). Montanhas pequenas, isoladas, mais próximas ao oceano e constantemente cobertas por neblina podem apresentar as mesmas características de florestas em altitudes mais elevadas, o que comumente é atribuído ao efeito de elevação de massa ou "Massenerhebung effect" (Grubb 1971; Flenley 1995). Uma vez que estas variações ambientais condicionam formas distintas de vegetação põem em dúvida limites altimétricos rígidos para a distribuição de algumas tipologias de vegetação, conforme explicitado em alguns sistemas de classificação da vegetação no Brasil (e.g., IBGE 2012; Veloso et al. 1991).

As especificidades ambientais em gradientes altitudinais imprimem mudanças significativas na estrutura da vegetação, porém, geralmente de forma gradativa (Klein 1980). Entretanto, estas variações podem ocorrer em dimensões espaciais muito exíguas, também relacionadas com a altitude, $\mathrm{pH}$ e umidade (tanto proveniente de precipitações quanto de neblinas) (Hemp 2006). Neste caso, variações ambientais abruptas poderiam determinar rupturas igualmente abruptas na variação da estrutura da vegetação ao longo de gradientes de altitude, desde que outros fatores ambientais estivessem envolvidos (geologia, geomorfologia, hidrologia e características pedológicas) e não somente a variação do clima local determinado pela variação da altitude. Essa é nossa hipótese fundamental e é através dela que elaboramos algumas perguntas de pesquisa referente à variação da vegetação ao longo de um gradiente altitudinal no Parque Botânico do Morro do Baú. São elas: há variação na composição florística da vegetação no gradiente altitudinal? Existindo diferença, seria gradativa ou abrupta? Quais fatores ambientais poderiam justificá-la? 
Tratando exclusivamente da vegetação do topo do Morro do Baú, a sua similaridade florística no contexto regional depende da altitude e/ou da proximidade geográfica?

O Vale do Itajaí, onde está inserida a área de estudo, possui vertente hidrológica voltada para leste, favorecendo a entrada de umidade proveniente do oceano Atlântico (Klein 1979; Aumond et al. 2009) que, juntamente com a geomorfologia e a altitude, determinam importante fonte de variação ambiental ao longo de sua extensão geográfica (Klein 1980). Diante desta amplitude de características ambientais em escala regional, bem como localmente, ao longo do gradiente do Morro do Baú, e suas consequências expressas nas formas de vegetação, acredita-se ser esta uma área adequada para responder às perguntas feitas anteriormente.

Por consequência, delimitou-se como principais objetivos diagnosticar a variação da vegetação arbórea ao longo de um gradiente altitudinal de Floresta Ombrófila Densa, discutir seus condicionantes, além de identificar similaridades na composição florística com áreas circunvizinhas de Floresta Atlântica.

\section{Material e Métodos}

Área de estudo

A área de estudo está inserida no Parque Botânico do Morro do Baú, município de Ilhota, estado de Santa Catarina, Sul do Brasil (Fig. 1; Reitz 1961). Para realização dos levantamentos do presente estudo, foram definidas três áreas de $5.000 \mathrm{~m}^{2}$ cada (total de 1,5 ha) em encosta voltada para oeste. As áreas foram distribuídas ao longo de um gradiente altitudinal nas seguintes cotas e coordenadas centrais: Área 1 - terço inferior da encosta, 340 m s.n.m. (264' 14,93”S, 48 56'36,38”O) em Floresta Ombrófila Densa Submontana (Ds) (IBGE 2012); Área 2 - terço médio da encosta, $540 \mathrm{~m}$

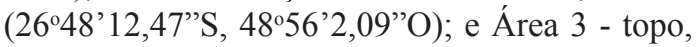

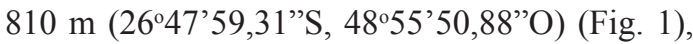
ambas em Floresta Ombrófila Densa Montana (Dm) (IBGE 2012).

De acordo com a classificação climática de Köppen, na faixa leste de Santa Catarina, onde está inserida a área de estudo, ocorre predomínio do Clima Subtropical mesotérmico úmido com verão quente - Cfa (Kottek et al. 2006). A umidade



Figura 1 - Mapas de localização e imagem com destaque para as áreas de estudo (Área 1, 2 e 3), e os limites do Parque Botânico do Morro do Baú e da Bacia Hidrográfica do Rio Itajaí (BHRI), Santa Catarina, Brasil. Adaptado de Epagri \& SDS (2005) e Google Earth (2016).

Figure 1 - Location maps and image highlighting study areas (Area 1, 2 and 3), and the borders of Morro do Baú Botanical Park (PBMB) and hydrographic basin of Rio Itajaí (BHRI), Santa Catarina, Brazil. 
relativa do ar regional situa-se, em média, entre 82 e 86\% (Klein 1979; Wrege et al. 2011) com frequentes nevoeiros que mantém a parte superior do Morro do Baú encoberta. A temperatura média anual é de $21^{\circ} \mathrm{C}$ (Klein 1979). A precipitação anual média regional é de 1.600 a $2.000 \mathrm{~mm}$ com chuvas bem distribuídas ao longo do ano, sendo a maior intensidade no verão (Klein 1979; Wrege et al. 2011).

O Parque Botânico do Morro do Baú encontra-se sobre a Formação Baú, pertencente ao Grupo Itajaí, parte do Escudo Catarinense, inserido na unidade geomorfológica de embasamentos em estilos complexos das Serras do Leste Catarinense (Santa Catarina 1986; Tomazzoli et al. 2012). O Grupo Itajaí, por sua vez, é constituído predominantemente por turbiditos (argilitos, siltitos e arenitos finos ritmicamente intercalados), conglomerados (Conglomerado Baú) e arenitos arcoseanos, bem como rochas vulcânicas e subvulcânicas de composição predominantemente riolítica, raramente básica, com raras camadas de tufos finos (Tomazzoli et al. 2012). Predominam relevos ondulados a montanhosos (Santa Catarina 1986), além de salientes escarpas.

A estratigrafia geológica supracitada, vinculada aos processos morfogenéticos, ensejam o predomínio de solos pouco desenvolvidos, dentre os quais Cambissolos e Neossolos (Potter et al. 2004). Em nível de correspondência específica, foi realizado levantamento pedológico por Caglioni (2017) nas respectivas áreas de estudo, com a abertura de dois perfis em cada piso altitudinal. Complementarmente, foram coletadas 22 amostras de solos, sendo oito na Área 1, oito na Área 2 e seis na Área 3 para confirmar o predomínio dos solos em toda área estudada. O levantamento pedológico revelou a ocorrência de Cambissolo Háplico $\mathrm{Tb}$ Alítico típico e Cambissolo Háplico Tb Alumínico típico, ambos com horizonte A moderado, textura argilosa em relevos que variam de ondulado a forte ondulado na Área 1. Na Área 2, por sua vez, há também o predomínio de Cambissolo Háplico $\mathrm{Tb}$ Alítico típico com as mesmas características de textura e relevo da Área 1. Por outro lado, a Área 3 possui grande diferenciação pedológica quando comparado com as demais, apresentando Espodossolo Humilúvico Tb Hidromórfico organossólico em relevo predominantemente ondulado.

O Morro do Baú é coberto pela Floresta Ombrófila Densa Submontana e Montana (IBGE 2012; Lingner et al. 2015), que, assim como em toda região, sofreu severamente com a exploração madeireira (Klein 1979). Neste local, a exploração ocorreu até a década de 60 principalmente nas áreas de menor altitude (Reitz 1961), com a retirada de espécies de alto valor econômico como canelas (Ocotea spp.) e perobas (Aspidosperma spp.), ocasionando a presença de manchas com vegetação em vários estágios de regeneração no interior do Parque (Klein 1979, 1980; Hoeltgebaum et al. 2013).

A partir de sua criação, em 1961 (Reitz 1961), a exploração madeireira cessou, porém iniciaramse os furtos frequentes de palmito juçara (Euterpe edulis Mart.), como relata Lisboa (2001).

\section{Coleta e análise dos dados}

Para o estudo da vegetação arbórea em cada um dos três pisos altitudinais, instalamos 50 parcelas contiguas com $100 \mathrm{~m}^{2}$ cada $(10 \mathrm{~m} \times 10$ m), totalizando 150 parcelas (Fig. 1; Áreas 1, 2 e 3) e 1,5 ha de área estudada.

Nas Áreas 1 e 2, em função de estreitos córregos que perpassam pelo centro das áreas de estudo, tomamos o cuidado de selecionar ambientes semelhantes em cada margem e com pouca influência direta dos cursos hídricos, para instalação das parcelas, diminuindo, desta forma, a presença de solos com regimes hídricos saturados a semi saturados, consequentemente eliminando possíveis tendências destas condições nos nossos resultados.

$\mathrm{Na}$ Área 3, em função das características da vegetação, classificamos os espécimes quanto ao seu grau de inclinação e enquadramos em duas categorias: retos, quando apresentavam o fuste em posição vertical ou com leve inclinação de até 10 graus e; inclinados, quando os fustes dos indivíduos apresentavam inclinação maior que 10 graus.

Em cada parcela, realizamos a medição do perímetro à altura do peito (PAP - 1,30 m) de todos os indivíduos arbóreos e samambaias (xaxins) que apresentaram valor maior ou igual a $15 \mathrm{~cm}$. Paralelamente, afixamos plaquetas de alumínio enumeradas em cada indivíduo vivo, facilitando sua localização e possibilitando a continuidade do estudo no futuro.

Amostras de material botânico que não identificamos em campo foram herborizadas e levadas ao laboratório para posterior identificação. Para isso, realizamos comparações com as coleções depositadas nos herbários Dr. Roberto Miguel Klein, da Universidade Regional de Blumenau (FURB), e Museu Botânico Municipal de Curitiba 
(MBM), além de consultas à literatura e a especialistas. Paralelamente, coletamos material fértil para depósito no Herbário do Departamento de Botânica da Universidade Federal do Paraná (UPCB) e Herbário FURB. A classificação das famílias de angiospermas foi baseada no sistema APG IV (2016). Para as samambaias, o sistema PPG I (2016), além de consultas à Flora do Brasil 2020 (em construção).

A partir da lista de espécies, elaboramos diagrama de Venn, evidenciando espécies comuns e exclusivas das três áreas estudadas (veja material suplementar em $<$ https://doi. org $/ 10.6084 / \mathrm{m} 9$.figshare.7267352>). Para comparar a riqueza de espécies ao longo do gradiente altitudinal, construímos uma curva de rarefação de espécies para cada área de estudo. Para isto, estruturamos uma matriz binária de espécies (presença/ausência) por parcela e efetuamos os cálculos no programa Estimates (versão 9.1.0) seguindo as opções do programa (Colwell 2013), alterando apenas o número de aleatorizações $(\mathrm{n}=999)$.

A fim de verificar a existência de variação da vegetação no gradiente altitudinal e, caso positivo, verificar se a variação é gradativa ou abrupta, utilizamos técnicas de ordenação com diferentes propósitos. Empregando a mesma matriz binária aplicada na construção das curvas de rarefação, conduzimos uma Análise de Correspondência Corrigida (Detrended Correspondence Analysis - DCA; Hill \& Gauch 1980), antes eliminando as espécies consideradas raras, ou seja, as espécies com frequência menor ou igual a dois (30\%), pois estas costumam influenciar negativamente a ordenação (Hill \& Gauch 1980; Gauch 1982). Este procedimento teve a finalidade de determinar somente o comprimento do gradiente dos eixos (Ter Braak 1995), tendo em vista as limitações de interpretação impostas pelos procedimentos de retificação dos escores dos eixos da DCA (McCune \& Mefford 2011). Para a ordenação dos dados, aplicamos à matriz binária a técnica de escalonamento multidimensional não-métrico (non-metric multidimensional scaling - NMDS), partindo de uma solução inicial 5-dimensional e buscando aquela que o "stress" fosse estabilizado (McCune et al. 2002) e assegurada a significância através de permutações Monte Carlo $(\mathrm{n}=999)$. Avaliamos os resultados através de diagramas bidimensionais e o "stress" foi verificado através da construção de diagramas de Shepard (Shepard 1962; Legendre \& Legendre 1998).
Partindo do pressuposto que a maior altitude deveria determinar aumento de similaridade da Área 3 com demais levantamentos de vegetação em altitudes mais elevadas, os resultados desta pesquisa (Áreas 1, 2 e 3) foram comparados com dados de unidades amostrais (UAs) do Inventário Florístico Florestal de Santa Catarina (IFFSC). Para isto, foram adotados os resultados obtidos por Lingner et al. (2015) que segregaram as UAs do IFFSC com altitudes superiores a $500 \mathrm{~m}$ em Floresta Ombrófila Densa Montana. Desta forma, foram selecionadas aquelas UAs inseridas na Dm com altitudes superiores a $500 \mathrm{~m}$ (Vibrans et al. 2013a), bem como aquelas contidas em um perímetro de $20 \mathrm{~km}$ para além da transição entre a Dm e a Floresta Ombrófila Mista (M), também acima de $500 \mathrm{~m}$ de altitude (Fig. 2; Vibrans et al. 2013b) a fim de incluir algumas áreas com vegetação típica de Floresta Ombrófila Densa Altomontanas - Dl. Desta forma, obteve-se um conjunto composto por 125 UAs do IFFSC, com altitudes entre 503 e $1.560 \mathrm{~m}$, entre as latitudes $26^{\circ} 5^{\prime} 59^{\prime \prime}$ e $28^{\circ} 2742$ 'S e longitudes $48^{\circ} 46^{\prime} 48^{\prime \prime}$ e $51^{\circ} 1^{\prime} 48^{\prime \prime} \mathrm{W}$.

Sabendo que as UAs do IFFSC tinham 4.000 $\mathrm{m}^{2}$ (Vibrans et al. 2010), excluiu-se, por sorteio, 10 parcelas de cada área da presente pesquisa a fim de tornar as áreas cobertas por nosso levantamento equivalente àquelas. Assim, também foram eliminadas as árvores com PAP menor que $30 \mathrm{~cm}$. Desta forma, imprimiu-se maior legitimidade às comparações com os dados do IFFSC. Através deste procedimento, obteve-se uma matriz composta de 569 espécies. Posteriormente, foram eliminadas as espécies com frequência menor ou igual a três, diminuindo influências negativas na ordenação dos dados (Hill \& Gauch 1980; Gauch 1982), resultando em uma matriz composta por 327 espécies e 128 áreas amostrais.

Com base nesta matriz de dados, foram calculadas a distância euclidiana entre a Área 3 de nosso estudo e as 127 áreas estudadas (duas do presente trabalho e 125 do IFFSC), baseando o cálculo nas coordenadas geográficas planas (UTM) de cada uma. Também foram calculadas a dissimilaridade florística entre a Área 3 e os demais estudos através do índice de Bray-Curtis, incluindo as Áreas 1 e 2. Identificou-se aquelas áreas que foram classificadas pela equipe de campo do IFFSC como florestas altomontanas a fim de observar se estas, em particular, possuíam maior similaridade com o topo do Morro do Baú (Área 3). Aplicouse um teste de correlação a fim de verificar se a 


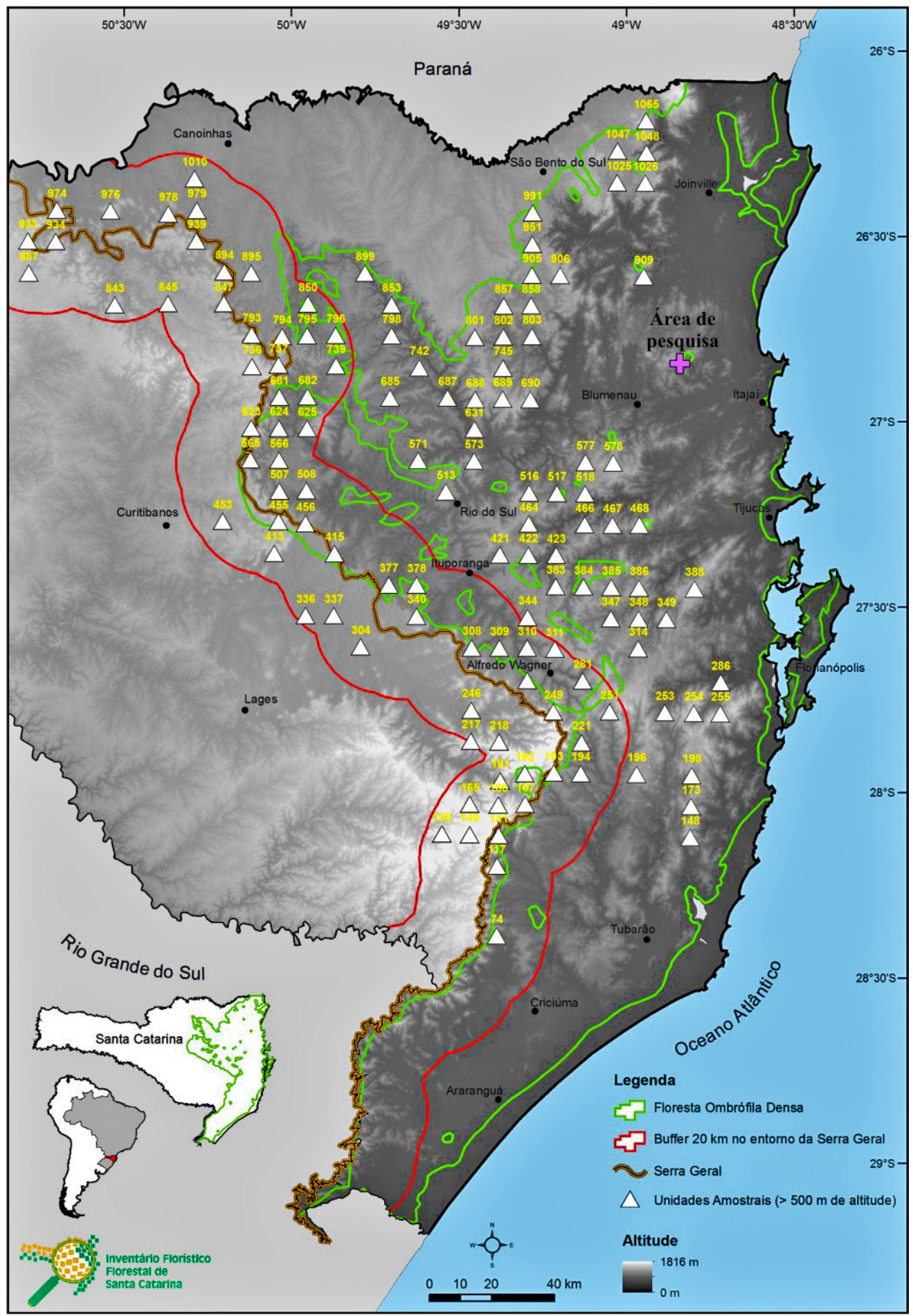

Figura 2 - Localização da Área de pesquisa e das unidades amostrais (UAs) do Inventário Florístico Florestal de Santa Catarina (IFFSC) implantadas na Floresta Ombrófila Densa e em perímetro de até $20 \mathrm{~km}$ além da transição entre a Floresta Ombrófila Densa e a Floresta Ombrófila Mista, em altitude superior a $500 \mathrm{~m}$. Fonte: Adaptado de Vibrans et al., (2012), por D.V. Lingner (2016).

Figure 2 - Research Area and sample units' (UAs) location of Santa Catarina's Forest Floristic Inventory (IFFSC) implanted in atlantic rain forest in a perimeter of up to $20 \mathrm{~km}$ beyond the transition between atlantic rain forest and Mixed Rain Forest, at an altitude higher than $500 \mathrm{~m}$. 
altitude e a proximidade espacial relacionavam-se com maior dissimilaridade florística. Também foi feito o cálculo da a média de dissimilaridade florística do conjunto de unidades amostrais, segmentando as unidades amostrais do IFFSC em oito intervalos altimétricos cujos limites inferiores foram: 500, 600, 700, 800, 900, 1.000, 1.100, 1.200 . Este resultado foi projetado graficamente a fim de verificar o comportamento da curva de tendência. Os procedimentos estatísticos foram conduzidos na plataforma R (R Core Team 2013) e o gráfico elaboramos no programa Microsoft Excel 2010.

\section{Resultados}

\section{Estrutura e dissimilaridade}

da composição florística

A vegetação da Área 1 é composta por 955 indivíduos, pertencentes a 125 espécies, 80 gêneros e 45 famílias. Na Área 2 foram registrados 933 indivíduos, distribuídos em 103 espécies, 66 gêneros e 39 famílias. Em ambas figuram Myrtaceae, Lauraceae, Rubiaceae e Fabaceae como famílias mais ricas. A floresta da Área 3, por sua vez, foi a mais distinta quando comparado aos três locais estudados. Foram registrados 1.582 indivíduos, distribuídos em 47 espécies, 35 gêneros e 26 famílias. Destacaram-se como famílias mais ricas Lauraceae, Melastomataceae e Primulaceae. Nesta Área, 98,3\% dos indivíduos encaixaram-se na categoria inclinados.

Considerando todo o gradiente altitudinal estudado, mediu-se um total de 3.470 indivíduos (inclusive os mortos) pertencentes a 183 táxons (material suplementar), distribuídos em 110 gêneros e 60 famílias. Ficaram indeterminados apenas um a nível específico, um em nível de família e quatro em nível de gênero.

A comparação da riqueza entre as três Áreas resultou em apenas nove espécies comuns (Fig. 3). A menor semelhança foi observada entre as Áreas 1 e 3, com 12 registros, e a maior semelhança entre as Áreas 1 e 2, com 74 espécies. Proporcionalmente, a Área 3 apresentou maior número de espécies exclusivas (62\%), seguida pela Área $1(38 \%)$ e, finalmente, pela Área $2(22 \%)$. A Área 3 possui menor riqueza florística que as demais Áreas (Fig. 4). Apesar de terem 74 espécies em comum (Fig. 3), também as Áreas 1 e 2 possuem riqueza significativamente diferente (Fig. 4).

A forte diferença na composição da flora entre os extremos da encosta - Áreas 1 e 3 (Fig. $3)$ é representada pelo resultado da aplicação da DCA (Tab. 1), revelando que o eixo DCA 1

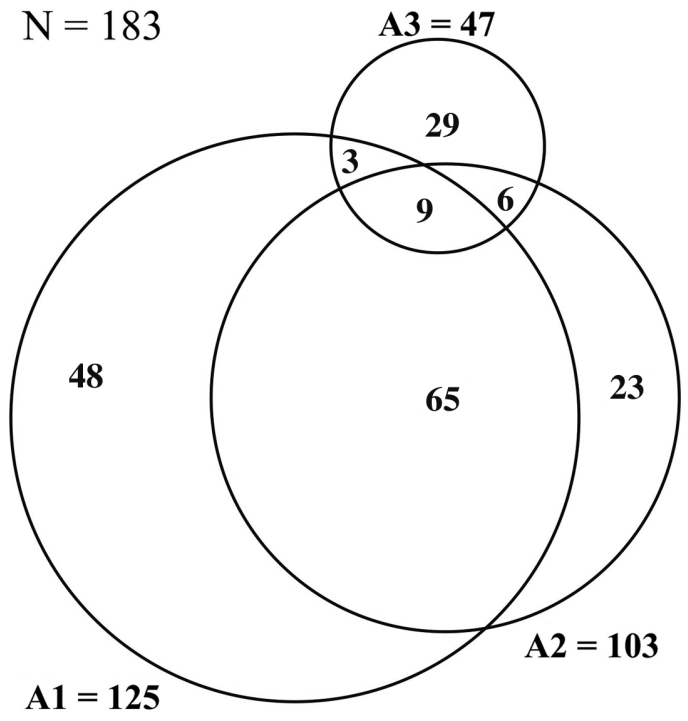

Figura 3 - Diagrama de Venn apresentando números de espécies comuns e exclusivas do componente arbóreo A1. área 1; A2. área 2; A3. área 3; N. número de táxons. Figure 3 - Venn Diagram showing number of common and exclusive species of the arboreal component - A1. area 1; A2. area $2 ; \mathrm{A} 3$. area $3 ; \mathrm{N}$. number of species.

capturou a maior parte da variação contida na matriz de dados (autovalor $1=0,892$ ) redundando em maior comprimento do gradiente capturado por este eixo da ordenação $(5,364)$. Os autovalores do segundo e do terceiro eixos foram mais baixos (DCA 2 - 0,266 e DCA 3 - 0,225, respectivamente), tendo como resultado gradientes bem mais curtos

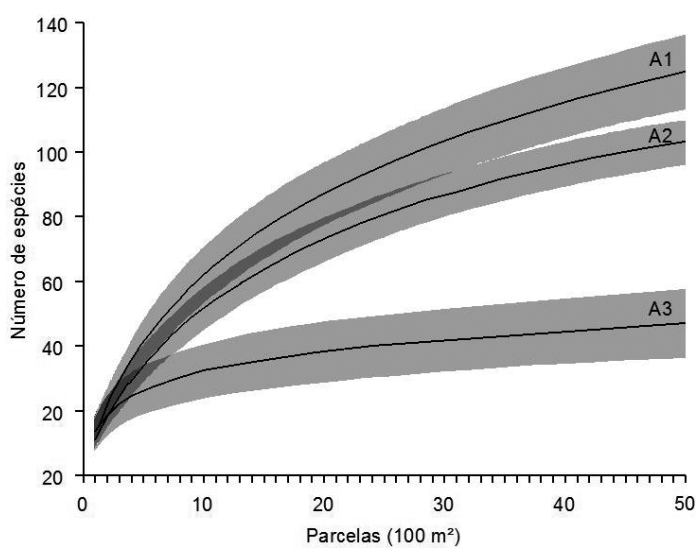

Figura 4-Curva de rarefação de espécies do componente arbóreo nas três áreas de estudo. (Hachurado = intervalo de confiança 95\%).

Figure 4-Rarefaction curve of species from arboreal component in the three study areas. (Hatched = confidence interval of 95\%). 
Tabela 1 - Autovalores e comprimento do gradiente dos eixos da análise de correspondência retificada (DCA), aplicada ao componente arbóreo nas três áreas estudadas.

Table 1 - Eigenvalues and gradient's length from rectified correspondence analysis' axes (DCA), applied to the arboreal component in the three studied areas.

\begin{tabular}{lcc}
\hline Eixo & Autovalor & Comprimento do Gradiente \\
\hline DCA 1 & 0,892 & $5,364^{* *}$ \\
DCA 2 & 0,266 & $3,331^{* *}$ \\
DCA 3 & 0,225 & $3,276^{*}$ \\
\hline
\end{tabular}

** significativo $1 \%$; $*$ significativo $5 \%, * *$ significant $1 \%$; significant $5 \%$.

(3,331 e 3,276, respectivamente). De fato, o gradiente longo determinado pelo DCA 1 (Tab. 1), é aquele que apresenta uma ruptura abrupta de similaridade entre as Áreas 1 e 2 com a 3, corroborando representação gráfica da ordenação por NMDS (Fig. 5) que permite verificar esta mesma polarização. A aplicação da NMDS reduziu os dados originais, apontando para uma solução unidimensional significativa após as permutações Monte Carlo $(p<0,01)$, tendo estabilizado o "stress" (em 19,84) e não sendo detectadas instabilidades acima de $3,8 \times 10^{-4}$.

Comparação entre as áreas de estudo e as unidades amostrais do IFFSC

Quando confrontados os dados obtidos pelo nosso estudo e aqueles obtidos através das amostras do IFFSC, verificou-se a existência de correlações significativas entre a dissimilaridade florística (medida através do índice de Bray-Curtis) e a distância espacial (medida através da distância

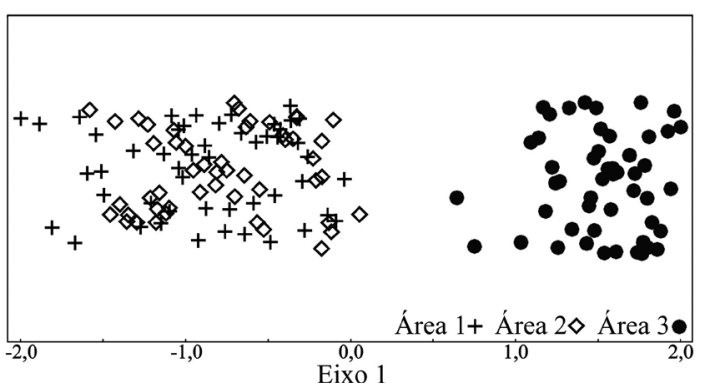

Figura 5 - Diagrama de ordenação apontando a distribuição das parcelas amostradas nas Áreas 1, 2 e 3 após a aplicação do escalonamento multidimensional nãométrico (non-metric multidimensional scaling) - NMDS. Figure 5-Order diagram showing distribution of sampled parcels in Area 1, 2 and 3 after applying non-metric multidimensional scaling - NMDS. euclidiana), bem como quando compara-se esta mesma dissimilaridade florística com a altitude. Respectivamente, os coeficientes de correlação foram de 0,403 e 0,200, ambos significativos ( $p$ $<0,05$ ). Isso mostra que quanto mais distantes e mais elevados os pontos de amostragem do IFFSC estão de nossa área de estudo, mais dissimilares eles serão, ou seja, unidades amostrais do IFFSC mais próximos e com altitudes mais semelhantes com a Área 3 possuem maior similaridade florística.

Considerada a dissimilaridade média em patamares de altitude (intervalos de 100 $\mathrm{m})$, verificou-se que a dissimilaridade tende a diminuir, atingindo seu pico até a faixa altitudinal de 900-1.000 m. Ao longo dos intervalos de altitude superior, esta tendência se inverte e a dissimilaridade média aumenta acima dos $1.000 \mathrm{~m}$ (Fig. 6). A dissimilaridade entre a Área 3 e as UAs do IFFSC levantadas em florestas reconhecidas em campo como altomontanas foi relativamente elevada (entre 0,72 e 0,91), mas estão todas

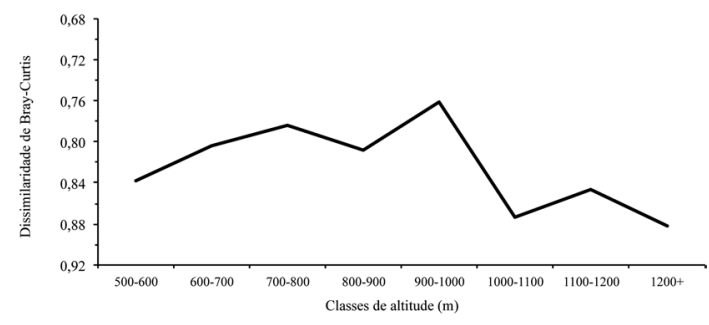

Figura 6 - Dissimilaridade Bray-Curtis média de cada intervalo altimétrico entre a Área 3 e as unidades amostrais do Inventário Florístico Florestal de Santa Catarina - IFFSC com altitude superior a $500 \mathrm{~m}$.

Figure 6 - Average Bray-Curtis dissimilarity of each altimetric interval between Area 3 and sample units from Santa Catarina's Forest Floristic Inventory (IFFSC), at an altitude higher than $500 \mathrm{~m}$. 
situadas para além de um raio de $50 \mathrm{~km}$ de distância do Morro do Baú. Dentre as 22 UAs do IFFSC que possuíam maior similaridade com a Área 3, nenhuma foi classificada em campo como floresta altomontana.

\section{Discussão}

A Área 3 possui características singulares quando comparada à composição florística das Áreas 1 e 2. Em relação a estas, há substituição de algumas famílias com maior riqueza, destacandose Lauraceae, Melastomataceae e Primulaceae, comumente famílias ricas em outros estudos de florestas altomontanas (Koehler et al. 2002; Scheer et al. 2011b; Vieira et al. 2014). Esta dissimilaridade, tanto no nível de famílias quanto de espécies, entre as Áreas do Morro do Baú, fornece elementos que corroboram a nossa hipótese de existência de uma transição abrupta da vegetação do topo e das encostas da área de estudo. Por outro lado, esta ruptura aproxima a Área 3 das típicas florestas altomontanas. De fato, Roderjan et al. (2002) apontaram oito espécies típicas destes ambientes, das quais cinco foram levantadas na Área 3 do presente trabalho (espécies indicadas no material suplementar).

Por sua vez, as características florísticas das Áreas 1 e 2 são típicas da vegetação de encosta do Vale do Itajaí, destacando as famílias Myrtaceae, Lauraceae, Rubiaceae e Fabaceae com maior representatividade, corroborando outros estudos na região (Klein 1979, 1980; Lisboa 2001; Caglioni et al. 2015) e também na Floresta Ombrófila Densa catarinense (Lingner et al. 2015) e paranaense (Scheer \& Blum 2009). A ocorrência de muitas espécies pertencentes a estas famílias é característica da Floresta Atlântica (OliveiraFilho \& Fontes 2000), principalmente em sua fase avançada (Leitão-Filho 1993; Joly et al. 2012).

Ao longo de um gradiente altimétrico ascendente a riqueza diminui, ocorrendo substituição gradativa de espécies (Klein 1979, 1980; Roderjan 1994; Joly et al. 2012). Neste sentido, as Áreas 1 e 2 possuem riquezas gradualmente dissimilares (Figs. 3 e 4), mas a riqueza da Área 3 é dramaticamente reduzida em comparação com as demais (Fig. 4), o que é ratificado pela completa segregação na representação gráfica da ordenação por NMDS (Fig. 5), determinando um amplo comprimento do gradiente (Tab. 1) e fornecendo mais elementos à nossa hipótese de transição abrupta. Esta grande simplificação florística das associações arbóreas em ambientes altomontanos associa-se frequentemente ao porte reduzido e grande densidade dos indivíduos, como expresso na fisionomia da Área 3. São características comumente regidas por condicionantes climáticos e pedológicos mais restritivos ao desenvolvimento das árvores, como baixas temperaturas, ventos fortes e constantes, elevada nebulosidade e solos progressivamente mais rasos e de menor fertilidade (Hamilton et al. 1995; Juvik \& Nullet 1995; Roderjan et al. 2002).

De fato, ao longo de gradientes altitudinais ascendentes é recorrentemente observada a diminuição da riqueza de espécies (Roderjan 1994; Hamilton et al. 1995; Roderjan \& Grodzki 1999; Richter 2000; Roderjan et al. 2002; Blum et al. 2011; Ferreira et al. 2015). Por outro lado, condições climáticas semelhantes podem abrigar significativas diferenças na vegetação, mas que estão diretamente relacionadas com as condições dos solos (Klein 1980; Botrel et al. 2002; Carvalho et al. 2005a,b; Kotchetkoff-Henriques et al. 2005; Budke et al. 2006). Observadas estas fontes de variação ambiental, é esperado que espécies arbóreas dominantes possuam distribuições ecológicas distintas e que variam gradativamente ao longo de um gradiente de umidade e elevação (conceito de continuum; Whittaker 1967), ou de modo abrupto, em resposta às súbitas mudanças ambientais. Considerando que há $270 \mathrm{~m}$ de diferença altitudinal entre as Áreas 2 e 3 e 470 m entre as Áreas 1 e 3, e ainda que a variação de temperatura observada na Serra do Mar do Paraná, por Roderjan \& Grodzki (1999), Blum et al. (2011) e Maack (2012) foi respectivamente de 0,44, 0,56 e $0,50{ }^{\circ} \mathrm{C}$ a cada $100 \mathrm{~m}$, podemos inferir que existe uma diferença média de 1,2 a $1,5^{\circ} \mathrm{C}$ entre as Áreas 2 e 3 e de 2,1 a $2,6^{\circ} \mathrm{C}$ entre as Áreas 1 e 3. Seriam estas diferenças capazes de justificar a variação abrupta da vegetação? Devem haver outros condicionantes.

A Área 3 está em zona nuvígea, ficando encoberta por nevoeiro principalmente no outono, inverno e início da primavera (Klein 1979). Apesar do entorno do Morro do Baú receber chuvas regularmente distribuídas durante todo o ano (Klein 1979; Wrege et al. 2011), a frequência de nuvens envolvendo o seu topo (originando a chamada chuva horizontal, conforme definido por Bruijnzeel \& Proctor 1995) deve gerar o efeito de elevação de massa (Massenerhebung, Grubb 1971; Flenley 1995), favorecido pela proximidade do oceano e pela sua elevada projeção altitudinal em relação ao contexto de seu entorno (trata-se de um morro testemunho isolado, na descrição 
de Aumond et al. 2009). Certamente, uma das consequências deste fenômeno é o aumento significativo do aporte hídrico neste ambiente (Bruijnzeel \& Proctor 1995).

Por certo que os efeitos sobre a vegetação se fazem sentir em muitos aspectos. Árvores com folhas de menor tamanho (consequentemente maior superfície específica), dossel mais denso, associado com elevada densidade e cobertas por grande quantidade de epífitos (Bruijnzeel \& Proctor 1995; Roderjan et al. 2002; Hölscher et al. 2004; Bruijnzeel et al. 2011), favorecem a formação de "cílios" que interceptam e condensam a umidade proveniente da neblina, conduzindo-a para os solos (Bruijnzeel \& Proctor 1995; Hamilton et al. 1995; Bruijnzeel et al. 2011).

Para adicionar mais elementos que justificam as diferenças entre a Área 3 e as demais, o elevado teor de matéria orgânica no horizonte hístico do Espodossolo (Caglioni 2017) favorece, não somente a retenção de água mas, sobretudo, a preservação desta no seu perfil, o que juntamente com as baixas temperaturas, resulta na diminuição da taxa de decomposição (Edwards \& Grubb 1977). Concomitante a isto, o relevo pouco movimentado propicia diferenças significativas na constituição dos solos em relação às Áreas 1 e 2 (Caglioni 2017). Em seu topo, o Morro do Baú tem rochas dispostas em camadas superpostas pouco inclinadas (o que determina o relevo descrito acima), formando mesetas estruturais de conglomerados e arenitos. A orientação das camadas pouco inclinadas e a forte cimentação por sílica neste, confere grande resistência dessa rocha à erosão diferencial (Aumond et al. 2009; Tomazzoli et al. 2012), fazendo com que esta superfície seja preservada, projetando-a em elevação (Tomazzoli et al. 2012).

Sobre este pacote, os Espodossolos Humilúvicos predominam na Área 3 (Caglioni 2017). A presença do horizonte B espódico (ortstein), subjacente ao horizonte hístico, dificulta ainda mais a drenagem e a pequena espessura efetiva dos solos (decorrente da formação do horizonte espódico), bem como a baixa densidade do horizonte hístico (sobrejacente ao horizonte espódico) devem gerar instabilidade e elevada frequência de tombamentos dos indivíduos (Scheer et al. 2011a), justificando o elevado número de árvores inclinadas na Área 3 (98,3\%). Deste conjunto de condições, deve decorrer uma elevada seletividade florística (Klein 1980; Hamilton et al. 1995; Roderjan et al. 2002; Scheer et al. 2011a; Joly et al. 2012; Pereira \& Almeida 2012).
Em contraposição, as Áreas 1 e 2, instaladas em solos profundos, argilosos, e bem drenados, devem propiciar características favoráveis para o desenvolvimento da vegetação, principalmente nos quesitos de riqueza, porte e densidade de indivíduos, relatado por Klein $(1979 ; 1980)$ como fitofisionomias características da vegetação de encostas do Vale do Itajaí.

Em suma, solos ricos em matéria orgânica, com elevado conteúdo de água (tanto pela elevada captura de umidade atmosférica, quanto pelo impedimento de drenagem e elevada capacidade de retenção hídrica dos solos), além de temperaturas mais baixas, são certamente fatores a serem considerados na avaliação da singularidade ambiental da Área 3, conduzindo, enfim, à constituição de condições que justificariam o estabelecimento de uma floresta com características florísticas e fisionômicas de floresta altomontana.

As comparações da Área 3 com demais levantamentos regionais, através das análises que empregaram os dados dos levantamentos realizados pelo IFFSC, apontaram para uma relação significativa $(\mathrm{p}<0,05)$ entre o índice de dissimilaridade Bray-Curtis e a distância euclidiana, bem como com a altitude. Portanto, áreas muito altas (e que, de um modo geral, estão também muito distantes) ou muito baixas, são mais dissimilares em relação à Área 3. Isso mostra que quanto mais próxima da Área 3 e quanto mais próxima da faixa altitudinal situada entre $800 \mathrm{~m}$ e $1.000 \mathrm{~m}$ um determinado fragmento de vegetação estiver, maior será a chance de ter similaridade florística com a Área 3, mas boa parte destas áreas não foi descrita em campo como uma verdadeira floresta altomontana. A imensa maioria das UAs levantadas através do IFFSC que apresentaram maior similaridade com a floresta da Área 3, de fato, não se constitui fisionomicamente em florestas altomontanas.

As análises realizadas em escala local (Fig. 5; Tab. 1) distanciaram a Área 3 do conjunto formado pelas Áreas 1 e 2 (todas situadas muito próximas geograficamente, mas em menor altitude), e as análises feitas em escala regional levam à conclusão de que quanto mais próximas geograficamente e mais aproximadas da faixa dos $800 \mathrm{~m}$ de altitude as unidades amostrais do IFFSC estiverem, mais assemelhadas elas serão à Área 3 (Fig. 6), independentemente de terem sido classificadas fisionomicamente como florestas altomontanas. Logo, conclui-se que a o topo do Morro do Baú abriga uma floresta altomontana, 
mas muito dissimilar floristicamente àquelas que regionalmente foram reconhecidas como tal pelo levantamento do IFFSC.

Resta a evidência de que florestas altomontanas não dependem somente da altitude para sua formação (Grubb 1971; Flenley 1995), mas de uma sutil relação entre todos os fatores anteriormente discutidos e que certamente gera a brutal dissimilaridade entre o topo e as encostas do Morro do Baú. Este modelo, no entanto, ainda carece de estudos mais profundos para que possa ser validado para a região.

\section{Conclusões}

A análise comparativa da composição florística das Áreas 1, 2 e 3 indica que as duas primeiras são muito distintas desta última, identificando assim uma transição abrupta entre estas e sustentando nossa hipótese alternativa. Acreditamos que um conjunto de fatores, não somente a altitude e suas implicações climáticas, mas também a geologia e a geomorfologia do Morro do Baú e a atuação do conjunto na formação dos solos, sejam os responsáveis pelo estabelecimento da floresta altomontana em seu topo, cuja flora é dissimilar em relação ao seu entorno. Regionalmente, a similaridade florística parece ser dependente da proximidade geográfica e da altitude, o que implica em aceitar que não necessariamente a maior similaridade se dá entre florestas fisionomicamente identificadas como altomontanas nos trabalhos utilizados para comparação. Logo, se aceitos estes argumentos, a origem das florestas altomontanas parece não depender somente da altitude, mas sim de conjuntos interatuantes de fatores.

\section{Agradecimentos}

À Universidade Federal do Paraná e ao programa de Pós-graduação em Engenharia Florestal; à CAPES, a bolsa de Doutorado do primeiro autor; ao Inventário Florístico Florestal de Santa Catarina, por disponibilizar informações que auxiliaram nas discussões dos resultados deste trabalho; à Embrapa Florestas; a Marcos Wigo; aos pesquisadores que auxiliaram na identificação de espécies: Dr. Alexandre Quinet, Dr. André L. de Gasper, M.Sc. Elton J. de Lírio, M.Sc. Marcelo L. Brotto, Dr. Marcos Sobral, Dra. Maria de F. Freitas, Dr. Renato Goldenberg; aos Herbários do Museu Botânico Municipal de Curitiba (MBM), da Universidade Regional de Blumenau (FURB) e Barbosa Rodrigues (HBR).

\section{Referências}

APG IV (2016) An update of the Angiosperm Phylogeny Group classification for the orders and families of flowering plants: APG IV. Botanical Journal of the Linnean Society 181: 1-20. Disponível em $<$ http:// reflora.jbrj.gov.br/downloads/2016_GROUP Botanical Journal of the Linnean Society.pdf $>$ Acesso em 3 março 2017.

Aumond JJ, Sevegnani L, Tachini M \& Bacca LE (2009) Condições naturais que tornam o Vale do Itajaí sujeito aos desastres. In: Frank B, Sevegnani L \& Tomaselli CC (eds.) Desastre de 2008 no Vale do Itajaí. Água, gente e política. Agência de Água do Vale do Itajaí, Blumenau. Pp. 22-37.

Blum CT, Roderjan CV \& Galvão F (2011) O clima e sua influência na distribuição da Floresta Ombrófila Densa na Serra da Prata, Morretes, Paraná. Floresta 41: 589-598.

Botrel RT, Oliveira-Filho AT, Rodrigues LA \& Curi N (2002) Influência do solo e topografia sobre as variações da composição florística e estrutura da comunidade arbóreo-arbustiva de uma floresta estacional semidecidual em Ingaí, MG. Revista Brasileira de Botânica 25: 195-213. Disponível em <http://www.scielo.br/scielo.php?script=sci arttext\&pid=S0100-84042002000200008\&lng=pt $\& n r m=$ iso \&tlng $=\mathrm{pt}>$. Acesso em 6 novembro 2012 .

Bruijnzeel LA \& Proctor J (1995) Hydrology, and biogeochemistry of Tropical Montane Cloud Forest: what do we really know? In: Hamilton L, Juvik JO \& Scatena FN (eds.) Tropical Montane Cloud Forests. Springer, New York. Pp. 38-78.

Bruijnzeel LA, Mulligan M \& Scatena FN (2011) Hydrometeorology of tropical montane cloud forests: emerging patterns. Hydrological Processes 25: 465-498.

Budke JC, Jarenkow JA \& Oliveira-Filho AT (2006) Relationships between tree component structure, topography and soils of a riverside forest, Rio Botucaraí, Southern Brazil. Plant Ecology 189: 187-200.

Caglioni E (2017) Gradientes ambientais e sua influência na variação da estrutura da vegetação no Parque Botânico do Morro do Baú - SC. Tese de Doutorado. Universidade Federal do Paraná, Curitiba. 149p.

Caglioni E, Curcio GR, Uhlmann A \& Bonnet A (2015) Estrutura e diversidade do componente arbóreo de Floresta Atlântica no Parque Nacional da Serra do Itajaí, Santa Catarina. Floresta 45: 289-302.

Carvalho DA, Oliveira-Filho AT, van den Berg E, Fontes MAL, Vilela EA, Marques JJGSM, Carvalho WAC (2005a) Variações florísticas e estruturais do componente arbóreo de uma Floresta Ombrófila Alto-Montana às margens do Rio Grande, Bocaina de Minas, MG, Brasil. Acta Botanica Brasilica 19: 91-109. Disponível em <http://www.scielo.br/ 
pdf/\%0D/abb/v19n1/v19n1a09.pdf $>$. Acesso em 6 outubro 2016.

Carvalho DA, Oliveira-Filho AT, Vilela EA, Curi N, Van Den Berg E, Fontes MAL \& Botezelli L (2005b) Distribuição de espécies arbóreo-arbustivas ao longo de um gradiente de solos e topografia em um trecho de floresta ripária do Rio São Francisco em Três Marias, MG, Brasil. Revista Brasileira de Botânica 28: 329-345.

Colwell RK (2013) EstimateS: statistical estimation of species richness and shared species from samples. Version 9.1. Disponível em $<$ http://purl.oclc.org/ estimates $>$. Acesso em 21 julho 2016.

Curcio GR, Uhlmann A \& Sevegnani L (2006) A Geopedologia e sua influência sobre espécies arbóreas de florestas fluviais. Embrapa Florestas, Colombo. 32p.

Edwards PJ \& Grubb PJ (1977) Studies of mineral cycling in a montane rain forest in new guinea: the distribution of organic matter in the vegetation and soil. Journal of Ecology 65: 943-969. Disponível em <http://www. jstor.org/stable/2259387? origin $=$ crossref $>$ Acesso em 29 março 2017.

Eisenlohr PV, Alves LF, Bernacci LC, Padgurschi MCG, Torres RB, Prata EMB, Santos FAM, Assis MA, Ramos E, Rochelle ALC, Martins FR, Campos MCR, Pedroni F, Sanchez M, Pereira LS, Vieira SA, Gomes JAMA, Tamashiro JY, Scaranello MAS, Caron CJ \& Joly CA (2013) Disturbances, elevation, topography and spatial proximity drive vegetation patterns along an altitudinal gradient of a top biodiversity hotspot. Biodiversity and Conservation. 22: 27672783. Disponível em $<$ http://link.springer.com/ article/10.1007/s10531-013-0553-x>. Acesso em 18 março 2014.

Epagri \& SDS (2005) Mapa de Unidades Hidrográficas de Santa Catarina. Disponível em $<\mathrm{http}$ ://ciram.epagri. sc.gov.br/mapoteca/>. Acesso em 12 setembro 2014.

Ferreira TS, Higuchi P, Silva AC, Mantovani A, Marcon AK, Salami B, Buzzi Junior F, Ansolin RD, Angélica MAB, Rosa D (2015) Distribuição e riqueza de espécies arbóreas raras em fragmentos de Floresta Ombrófila Mista ao longo de um gradiente Altitudinal, em Santa Catarina. Revista Árvore 39: 447-455. Disponível em <http://www. scielo.br/scielo.php?script=sci_arttext\&pid=S0100$67622015000300447 \& \operatorname{lng}=\mathrm{pt} \& \mathrm{Erm}=\mathrm{iso} \& \operatorname{tlng}=\mathrm{en}>$. Acesso em 7 abril 2017.

Flenley JR (1995) Cloud forest, the Massenerhebung effect, and ultraviolet insolation. In: Hamilton L, Juvik JO \& Scatena FN (eds.) Tropical Montane Cloud Forests. Springer, New York. Pp. 150-155.

Flora do Brasil 2020 (em construção) Jardim Botânico do Rio de Janeiro, Rio de Janeiro. Disponível em $<$ http://floradobrasil.jbrj.gov.br/>. Acesso em 11 março 2016.

Gasper AL, Meyer L, Sevegnani L, Sobral MEG \& Bonnet A(2012) Flora vascular de Santa Catarina. In: Vibrans
AC, Sevegnani L, Gasper AL \& Lingner DV (eds.) Inventário florístico florestal de Santa Catarina. Vol I. Diversidade e conservação dos remanescentes florestais. Edifurb, Blumenau. Pp. 99-111.

Gauch HG (1982) Multivariate Analysis in Community Ecology. Cambridge University Press, Cambridge. 298 .

Google Earth (2016) Versão 7.1.2.2041. Disponível em $<$ https://www.google.com/earth/index.html $>$.Acesso em 1 agosto 2016.

Grubb PJ (1971) Interpretation of the "Massenerhebung" effect on tropical mountains. Nature 229: 4445. Disponível em <http://www.nature.com/ doifinder/10.1038/229044a0>. Acesso em 28 março 2017.

Hamilton L, Juvik JO \& Scatena FN (1995) Tropical Montane Cloud Forests. Springer, New York. 407p.

Hemp A (2006) Continuum or zonation? Altitudinal gradients in the forest vegetation of Mt. Kilimanjaro. Plant Ecology 184: 27-42. Disponível em <https:// link.springer.com/article/10.1007/s11258-005-90494>. Acesso em 29 março 2017.

Herrmann MLP \& Rosa RO (1990) Relevo. In: IBGE. Geografia do Brasil - Região Sul. IBGE, Rio de Janeiro. Pp. 55-84.

Hill MO \& Gauch HG (1980) Detrended correspondence analysis: an improved ordination technique. Vegetatio 42: 47-58.

Hoeltgebaum MP, Queiroz MH \& Reis MS (2013) Relação entre bromélias epifíticas e forófitos em diferentes estádios sucessionais. Rodriguésia 64: 337-347. Disponível em $<$ http://rodriguesia-seer.jbrj.gov.br/ index.php/rodriguesia/article/view/ID 549>. Acesso em 12 setembro 2013.

Hölscher D, Köhler L, Van Dijk AIJM \& Bruijnzeel LA (2004) The importance of epiphytes to total rainfall interception by a tropical montane rain forest in Costa Rica. Journal of Hydrology 292: 308-322.

IBGE (2012) Manual técnico da vegetação brasileira. IBGE, Rio de Janeiro. Disponível em $<$ http://scholar. google.com/scholar?hl=en\&btnG=Search\&q=intit le:Manual+Técnico+da+Vegetação+Brasileira\#0>. Acesso em 8 janeiro 2013.

Joly CA, Assis MA, Bernacci LC, Tamashiro JY, Campos MCR, Gomes JAMA, Lacerda MS, Santos FAM, Pedroni F, Pereira LS, Padgurschi MCG, Prata EMB, Ramos E, Torres RB, Rochelle A, Martins FR, Alves LF, Vieira SA, Martinelli LA, Camargo PB, Aidar MPM, Eisenlohr PV, Simões E, Villani JP \& Belinello R (2012) Florística e fitossociologia em parcelas permanentes da Mata Atlântica do Sudeste do Brasil ao longo de um gradiente altitudinal. Biota Neotropica 12: 123-145.

Juvik JO \& Nullet D (1995) Relationships between rainfall, cloud-water interception, and canopy throughfall in a Hawaiian Montane Forest. In: Hamilton L, Juvik JO \& Scatena FN (eds.) Tropical Montane Cloud Forests. Springer, New York. Pp. 165-182. 
Klein RM (1978) Mapa fitogeográfico do estado de Santa Catarina. Flora Ilustrada Catarinense. FATMA, Florianópolis. Herbário Barbosa Rodrigues, Itajai. $24 \mathrm{p}$.

Klein RM (1979) Ecologia da flora e vegetação do Vale do Itajaí. Sellowia 31: 1-164.

Klein RM (1980) Ecologia da flora e vegetação do Vale do Itajaí. Sellowia 32: 165-389.

Koehler A, Galvão F \& Longhi SJ (2002) Floresta Ombrófila Densa Altomontana: aspectos florísticos e estruturais de diferentes trechos na Serra do Mar, PR. Ciência Florestal 12: 27-39. Disponível em $<$ http://coral.ufsm.br/cienciaflorestal/artigos/v12n2/ A4V12N2.pdf $>$. Acesso em 8 julho 2015.

Kotchetkoff-Henriques O, Joly CA \& Bernacci LC (2005) Relação entre o solo e a composição florística de remanescentes de vegetação natural no Município de Ribeirão Preto, SP. Revista Brasileira de Botânica 28: 541-562.

Kottek M, Grieser J, Beck C, Rudolf B \& Rubel F (2006) World map of the Köppen-Geiger climate classification updated. Meteorologische Zeitschrift 15: 259-263.

Legendre P \& Legendre L (1998) Numerical ecology, $2^{\text {a }}$ ed. Elsevier Scientific Publishing Company, Amsterdam. $853 p$.

Leitão-Filho HF (1993) Ecologia da Mata Atlântica em Cubatão (SP). UNESP, Campinas. UNICAMP, Campinas. 184p.

Lingner DV, Schorn LA, Sevegnani L, Gasper AL, Meyer L \& Vibrans AC (2015) Floresta Ombrófila Densa de Santa Catarina - Brasil: agrupamento e ordenação baseados em amostragem sistemática. Ciência Florestal 25: 933-946. Disponível em $<$ http://cascavel.ufsm.br/revistas/ojs-2.2.2/index. $\mathrm{php} /$ cienciaflorestal/article/view/20595/pdf $>$. Acesso em 28 janeiro 2016

Lisboa RBZ (2001) Análise fitossociológica de uma comunidade arbórea na Floresta Ombrófila Densa, no Parque Botânico do Morro Baú, Ilhota/SC. Dissertação de Mestrado. Universidade Federal de Santa Catarina, Florianópolis. 132p.

Maack R (2012) Geografia física do estado do Paraná. $4^{\text {a }}$ ed. Editora UEPG, Ponta Grossa. 526p.

Maçaneiro JP, Oliveira LZ, Seubert RC, Eisenlohr PV \& Schorn LA (2016) More than environmental control at local scales: do spatial processes play an important role in floristic variation in subtropical forests? Acta Botanica Brasilica 30: 183-192.

McCune B, Grace JB \& Urban DL (2002) Analysis of ecological communities. MjM software, Gleneden Beach. Disponível em $<$ https://www.pcord.com/book. $\mathrm{htm}>$. Acesso em janeiro 2017.

McCune B \& Mefford MJ (2011) PC-ORD. Multivariate analysis of ecological data. Version 6.0. MjM software, Gleneden Beach. Disponível em $<$ https://www.pcord. com/PBooklet.pdf $>$. Acesso em janeiro 2017.
Oliveira-Filho AT \& Fontes MAL (2000) Patterns of floristic differentiation among Atlantic Forests in Southeastern Brazil and the influence of climate. Biotropica 32: 793-810.

Pereira JBS \& Almeida JR (2012) Biogeografia e geomorfologia. In: Guerra AJT \& Cunha SB (eds.) Geomorfologia e meio ambiente. Bertrand Brasil, Rio de Janeiro. Pp. 195-247.

Potter RO, Carvalho AP, Flores CA \& Bognola I (2004) Solos do estado de Santa Catarina. Embrapa Solos. Boletim de pesquisa e desenvolvimento, 46. Embrapa Solos, Rio de Janeiro. 721p.

PPG I (2016) A community-derived classification for extant lycophytes and ferns. Journal of Systematics and Evolution 54: 563-603. Disponível em <http:// onlinelibrary.wiley.com/doi/10.1111/jse.12229/ epdf>. Acesso em 3 março 2017.

R Core Team (2013) R: a language and environment for statistical computing. R Foundation for Statistical Computing. Vienna, Austria. Disponível em <http://www.R-project.org $>$. Acesso em 1 fevereiro 2016.

Reitz R (1961) Parque Botanico Morro do Baú. Sellowia 13: 9-15.

Richter M (2000) A hypothetical framework for testing phytodiversity in mountainous regions: the influence of airstreams and hygrothermal conditions. Phytocoenologia 30: 519-541.

Roderjan CV (1994) O gradiente da Floresta Ombrófila Densa no Morro Anhangava, Quatro Barras, PR - aspectos climáticos, pedológicos e fitossociológicos. Tese de Doutorado. Universidade Federal do Paraná, Curitiba. 119p.

Roderjan CV \& Grodzki L (1999) Acompanhamento meteorológico em um ambiente de Floresta Ombrófila Densa Altomontana do Morro Anhangava, mun. Quatro Barras - PR, no ano de 1993. Cadernos da Biodiversidade 2: 27-34.

Roderjan CV, Galvão F, Kuniyoshi YS \& Hatschbach GG (2002) As unidades fitogeográficas do estado do Paraná, Brasil. Ciencia \& Ambiente 24: 75-92.

Rodrigues LA, Carvalho DA, Oliveira-Filho AT \& Curi N (2007) Efeitos de solos e topografia sobre a distribuição de espécies arbóreas em um fragmento de Floresta Estacional Semidecidual, em Luminárias, MG. Revista Árvore 31: 25-35.

Santa Catarina (1986) Gabinete de planejamento e coordenação geral. Atlas de Santa Catarina. GAPLAN/SUEGI, Florianópolis. Aerofoto Cruzeiro, Rio de Janeiro. 173p.

Scheer MB \& Blum CT (2009) Arboreal diversity of the Atlantic Forest of Southern Brazil: from the beach ridges to the Paraná river. In: Grillo O \& Venora G (eds.) The dynamical processes of biodiversity - case studies of evolution and spatial distribution. Intech, Rijeka. Pp.109-134. Disponível em <https://www.intechopen.com/ books/the-dynamical-processes-of-biodiversity- 
case-studies-of-evolution-and-spatial-distribution/ arboreal-diversity-of-the-atlantic-forest-ofsouthern-brazil-from-the-beach-ridges-to-theparana-riv>. Acesso em 3 janeiro 2013.

Scheer MB \& Mocochinski AY (2009) Florística vascular da Floresta Ombrófila Densa Altomontana de quatro serras no Paraná. Biota Neotropica 9: 51-70. Disponível em <http://scholar.google.com/scholar ?hl=en\&btnG $=$ Search\&q=intitle:Florística + vascu lar + da + Floresta + Ombrófila + Densa + Altomontana + de + quatro + serras + no+Paraná\#0 $>$. Acesso em 15 novembro 2015.

Scheer MB, Curcio GR \& Roderjan CV (2011a) Funcionalidades ambientais de solos altomontanos na Serra da Igreja, Paraná. Revista Brasileira de Ciência do Solo 35: 1113-1126. Disponível em $<$ http://www.scielo.br/pdf/rbcs/v35n4/a05v35n4. pdf $>$. Acesso em 21 outubro 2015.

Scheer MB, Mocochinski AY \& Roderjan CV (2011b) Estrutura arbórea da Floresta Ombrófila Densa Altomontana de serras do Sul do Brasil. Acta Botanica Brasilica 25: 735-750. Disponível em $<$ http://www.scielo.br/pdf/abb/v25n4/02.pdf $>$. Acesso em 15 novembro 2012.

Scheer MB, Curcio GR \& Roderjan CV (2013) Carbon and water in upper montane soils and their influences on vegetation in Southern Brazil. ISRN Soil Science 2013: 1-12.

Shepard RN (1962) The analysis of proximities: multidimensional scaling with an unknown distance function. Psychometrika 27: 125-140. Disponível em <https://link.springer.com/article/10.1007/ BF02289630>. Acesso em 5 janeiro 2017.

Soares RV \& Batista AC (2004) Meteorologia e climatologia florestal. UFPR, Curitiba. 195p.

Ter Braak CFF (1995) Ordination. In: Jongman RHG, Ter Braak CJF \& Van Tongeren OFR (eds.) Data analysis in community and landscape ecology. Cambridge University Press, Cambridge. Pp. 91173.

Tomazzoli ER, Parizoto DGV, Abreu J \& Pellerin JRGM (2012) Análise e mapeamento das áreas de risco a movimentos de massa e inundações nos municípios de Gaspar, Ilhota e Luiz Alves (complexo do Morro do Baú), SC. Departamento de Geociências - UFSC, Florianópolis. 142p.

Uhlmann A, Gasper AL, Sevegnani L, Vibrans AC, Meyer L \& Lingner DV (2012) Fitogeografia de Santa Catarina. In: Vibrans AC, Sevegnani L, Gasper AL \& Lingner DV (eds.) Inventário Florístico Florestal de Santa Catarina. Vol I. Diversidade e conservação dos remanescentes florestais. Edifurb, Blumenau. Pp. 113-123.

Veloso H, Rangel-Filho A \& Lima J (1991) Classificação da vegetação brasileira adaptada a um sistema universal. IBGE, Departamento de Recursos Naturais e Estudos Ambientais, Rio de Janeiro. $124 \mathrm{p}$.

Vibrans AC, Sevegnani L, Gasper AL \& Lingner DV (2012) Diversidade e conservação dos remanescentes florestais. Vol. I. Edifurb, Blumenau. 344p.

Vibrans AC, Sevegnani L, Gasper AL \& Lingner DV (2013a) Floresta Ombrófila Densa (Vol. IV). Edifurb, Blumenau. 576p. Disponível em <http:// www.iff.sc.gov.br>. Acesso em 17 dezembro 2012.

Vibrans AC, Sevegnani L, Gasper AL \& Lingner DV (2013b) Floresta Ombrófila Mista. Vol III. Edifurb, Blumenau. 440p. Disponível em <http://www.iff. sc.gov.br>. Acesso em 9 abril 2013.

Vibrans AC, Sevegnani L, Lingner DV, Gasper AL \& Sabbagh S (2010) Inventário Florístico Florestal de Santa Catarina (IFFSC): aspectos metodológicos e operacionais. Pesquisa Florestal Brasileira 20: 291-302.

Vieira RS, Blum CT \& Roderjan CV (2014) Caracterização florística e estrutural de uma Floresta Ombrófila Densa Altomontana na Serra do Capivari, Campina Grande do Sul, Paraná. Floresta 44: 565-576. Disponível em <http://revistas.ufpr. br/floresta/article/view/33612/24039>. Acesso em 2 agosto 2016.

Whittaker RH (1967) Gradient analysis of vegetation. Biological Review 49: 207-264.

Wrege MS, Steinmetz S, Reisser Jr. C \& Almeida IR (2011) Atlas climático da Região Sul do Brasil: estados do Paraná, Santa Catarina e Rio Grande do Sul. Embrapa Clima Temperado, Pelotas. Embrapa Florestas, Colombo. 333p. 